\title{
GENETIC DIVERSITY IN SODIUM AZIDE-INDUCED BARLEY MUTANT LINES
}

\author{
B. Dyulgerova*, N. Dyulgerov \\ Institute of Agriculture - Karnobat, Bulgaria
}

\begin{abstract}
The aim of this study was to assess the diversity among sodium azide-induced mutants of winter 2-rowed barley for 8 quantitative traits of by multivariate analyses. Forty-seven mutant lines and their parental varieties Kuber, Zagorets, Asparuh, and Imeon were tested in complete block design with four replications. The studied traits included spike length, awn length, peduncle length, spikelet and grain number per spike, grain weight per spike, 1000 grain weight and grain yield. Principal component and cluster analyses were used for the assessment of mutants. Traits spike length, spikelet number per a spike, grain number per spike and grain weight per spike had the largest contribution to the divergence between mutants. The cluster and principal component analyses employed in the present study divided the mutant lines into different groups, which were deviated significantly from the respective parents. Diverse mutant lines with improved yield-related traits suitable for including in winter barley breeding program were identified.
\end{abstract}

Key words: mutants, quantitative traits, cluster analysis, principal component analysis

\section{INTRODUCTION}

Winter barley is an important crop for Bulgaria, mainly used for animal feed and for malting. Experimental mutagenesis had a major role in barley breeding and led to the development of varieties with tremendous impact on barley production (1). Above 300 barley varieties have been registered in FAO/IAEA Mutant Variety Database (2). As a result of mutation breeding at the Institute of Agriculture - Karnobat four new varieties of winter barley had been developed.

The availability of genetic variability is needed prerequisite in crop improvement programs (3). Successful selection of favorable segregants after hybridization depends largely on the selection of parents with high divergence for different traits (4). Therefore, knowledge of genetic divergence between mutant lines is fundamental in identifying the most suitable mutants for including in breeding work.

\footnotetext{
*Correspondence to: Boryana Dyulgerova, Institute of Agriculture, 8400 Karnobat, Bulgaria, Tel: +359878857911,e-mail: bdyulgerova@abv.bg
}

Multivariate analyses are routinely used for the assessment of the genetic divergence in germplasm collections. Cluster and principal component analyses have been widely used in studies for delineating with the variability among the genotypes (5-8).

The objective of this study was to assess the diversity among sodium azide-induced mutant lines of winter barley for 8 quantitative traits of by multivariate analyses.

\section{MATERIAL AND METHODS}

The study was carried out in the experimental field of the Institute of Agriculture-Karnobat, Southeastern Bulgaria during three consecutive years from 2014/2015 to 2016/2017. Totally, 47 mutant lines - 18 from variety Kuber, 10 from variety Zagorets, 10 from variety Asparuh and 9 from variety Imeon along with the 4 parent varieties were tested in a complete block design with four replications (Table 1). 
Table 1. List of mutant lines used in the study

\begin{tabular}{ll}
\hline Parental variety & Mutant lines \\
\hline Kuber & $16 / 1-1,16 / 1-3,16 / 1-4,16 / 1-8,16 / 1-10,16 / 1-13,16 / 1-14,16 / 1-$ \\
& $16,16 / 1-21,16 / 2-7,16 / 2-9,16 / 2-11,16 / 2-19,16 / 2-20,16 / 2-23$, \\
& $16 / 3-8,16 / 3-12,16 / 3-14$ \\
\hline Zagorets & $18 / 1-4,18 / 1-5,18 / 1-6,18 / 1-7,18 / 2-2,18 / 2-3,18 / 2-5,18 / 2-6$, \\
& $18 / 3-2,18 / 3-7$ \\
\hline Asparuh & $17 / 1-5,17 / 1-8,17 / 1-15,17 / 2-1,17 / 2-3,17 / 2-12,17 / 2-13,17 / 2-$ \\
& $14,17 / 2-17,17 / 3-2$ \\
\hline Imeon & $15 / 1-3,15 / 1-8,15 / 1-9,15 / 1-12,15 / 1-17,15 / 2-3,15 / 3-2,15 / 3-$ \\
& $6,15 / 3-7$ \\
\hline
\end{tabular}

Mutant lines were developed after mutant treatment of pre-soaked for $16 \mathrm{~h}$ seed of parental varieties with $2 \mathrm{mM}$ sodium azide for 2 hours. Mutants with desirable characteristics were selected from M2 to M6 generation. Selected advanced mutant lines were tested in the present study. Parental varieties Kuber, Zagorets, Asparuh and Imeon are winter malting 2-rowed barley varieties, released by the Institute of Agriculture - Karnobat (9-12).

The studied traits included spike length $(\mathrm{cm})$, awn length $(\mathrm{cm})$, peduncle length $(\mathrm{cm})$, spikelet number per spike, grain number per spike, grain weight per spike $(\mathrm{g}), 1000$ grain weight $(\mathrm{g})$, grain yield $(\mathrm{t} / \mathrm{ha})$. The data were measured on 10 randomly selected plants from each plot. Grain yield and 1000 grain weight were determined on a plot basis.

Two multivariate analyses - principal component and cluster analyses were utilized for the evaluation of mutants. The cluster analysis was done using squared Euclidian distance and the Ward's method as the clustering method (13). Before computing, data were standardized. All analyses were done using SPSS 16 for Windows (14).

\section{RESULTS}

Mean, range and coefficient of variation (CV) for 8 studied traits of 47 mutant lines and their parental varieties are presented in Table 2 . Maximum variation was observed for peduncle length with a CV of $10.47 \%$, followed by the awn length $(\mathrm{CV}=9.78 \%)$. The least variation with the CV of $3.65 \%$ was found for the 1000 grain weight. The length of spike ranged from $9.75 \mathrm{~cm}$ to $11.17 \mathrm{~cm}$, with $\mathrm{CV}=5.75 \%$. Spike and grain number varied from 25.00 to 33.05 and from 24.17 to 31.08 , respectively. The mean grain weight per spike was $1.51 \mathrm{~g}$ and varied from $1.34 \mathrm{~g}$ to $1.80 \mathrm{~g}$. The yield from the three years of study was $6.41 \mathrm{t} / \mathrm{ha}$ with $\mathrm{CV}=7.63 \%$

Table 2. Basic statistics for 8 traits of 47 mutant lines and their parent varieties

\begin{tabular}{lllll}
\hline Traits & Mean & Minimum & Maximum & $\mathbf{C V , \%}$ \\
\hline Spike length, cm & 9.75 & 8.53 & 11.17 & 5.75 \\
\hline Awn length, cm & 10.71 & 8.42 & 13.08 & 9.78 \\
\hline Peduncle length, cm & 18.63 & 15.00 & 23.96 & 10,47 \\
\hline Spikelet number per spike & 29.42 & 25.00 & 33.05 & 5.95 \\
\hline Grain number per spike & 28.06 & 24.17 & 31.08 & 5.87 \\
\hline Grain weight per spike, g & 1.51 & 1.34 & 1.80 & 6.07 \\
\hline 1000 grain weight, g & 45.89 & 41.65 & 50.38 & 3.65 \\
\hline Grain yield, t/ha & 6.41 & 5.09 & 7.23 & 7.63 \\
\hline
\end{tabular}

The dendrogram of the evaluated mutant lines and their parental varieties is presented in Figure 1. The studied mutant lines and their parents were grouped into 6 clusters based on 8 quantitative traits. Among the clusters, cluster
$\mathrm{F}$ had the largest number of genotypes - 12, cluster D had 11 genotypes and cluster A had 10 genotypes. Cluster $\mathrm{C}$ had 8 genotypes whereas both clusters $\mathrm{B}$ and $\mathrm{E}$ contained 5 genotypes. 


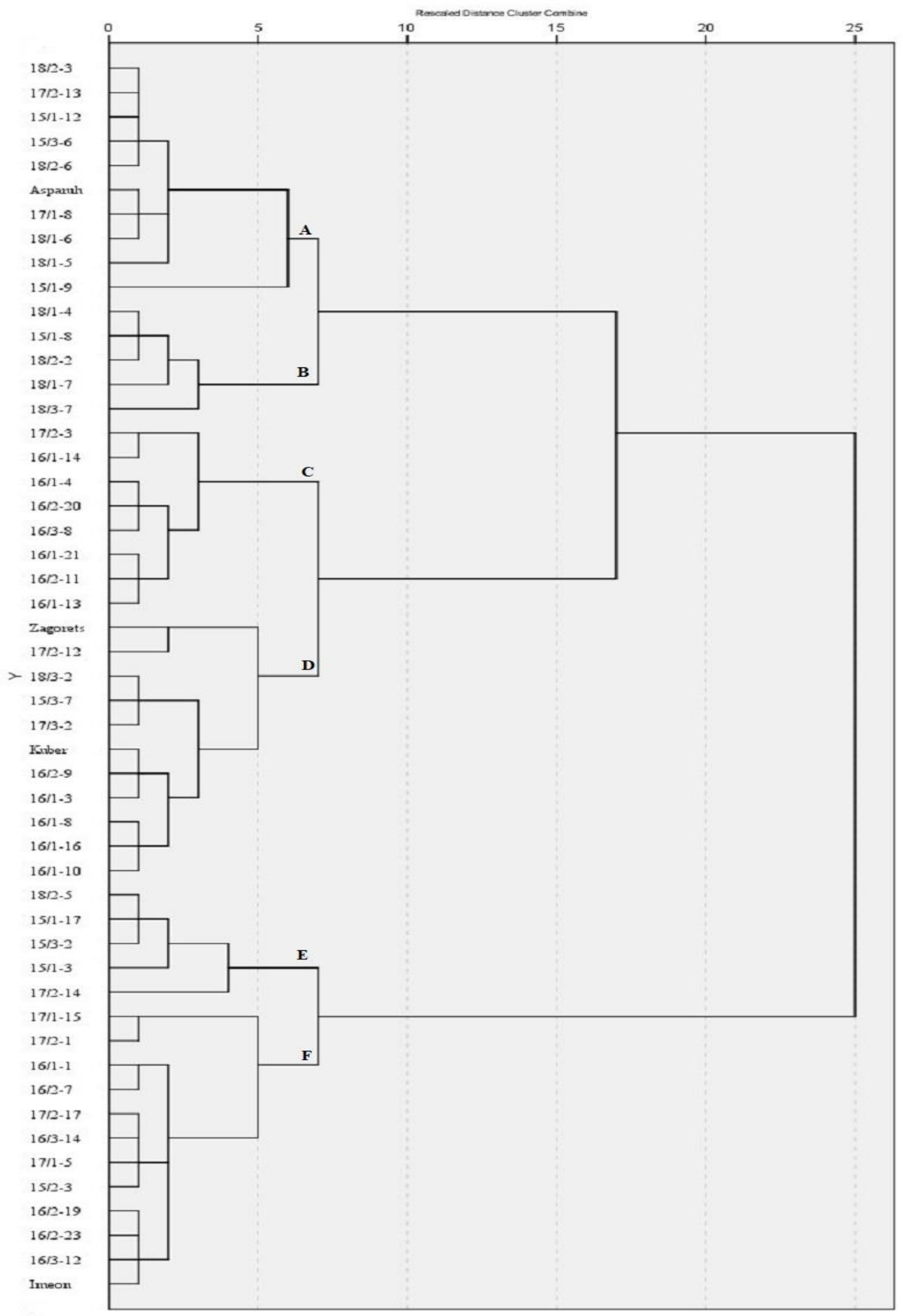

Figure 1. Cluster diagram of 47 mutant lines and their parent varieties for 8 quantitative traits 

The mean values for 6 clusters of the studied traits are presented in Table 3. The comparison of means of traits in different clusters showed that clusters $\mathrm{E}$ and $\mathrm{F}$ had the highest value for spike length, spikelet number per spike, grain number per spike and grain weight per spike.
DYULGEROVA B., et al. Cluster $\mathrm{C}$ had the highest mean value of yield and lowest for 1000 grain weight. Cluster A produced a maximum of 1000 grains weight. Cluster B had the lowest weight of 1000 grains and grain yield.

Table 3. Cluster means for 8 traits of 47 mutant lines and their parent varieties

\section{Traits Cluster}

\begin{tabular}{llllllc}
\hline & A & B & C & D & E & F \\
\hline SL & 9.83 & 9.31 & 9.22 & 9.53 & 10.43 & 10.16 \\
\hline AL & 11.33 & 11.41 & 9.54 & 10.12 & 12.39 & 10.52 \\
\hline PL & 17.88 & 16.03 & 17.97 & 20.31 & 18.01 & 19.48 \\
\hline SNS & 29.78 & 27.65 & 27.36 & 28.73 & 31.17 & 31.15 \\
\hline GNS & 28.40 & 25.95 & 26.50 & 27.34 & 29.52 & 29.74 \\
\hline GWS & 1.52 & 1.40 & 1.43 & 1.50 & 1.67 & 1.55 \\
\hline TGW & 46.70 & 46.13 & 44.76 & 46.56 & 46.17 & 45.15 \\
\hline GY & 5.98 & 5.76 & 6.81 & 6.57 & 6.64 & 6.56 \\
\hline
\end{tabular}

SL - spike length, cm; AL - awn length, cm; PL - peduncle length, cm; SNS - spikelet number per spike; GNS - grain number per spike; GWS - grain weight per spike, g; TGW - 1000 grains weight, cm; GY - grain yield, t/ha;

Principal component analysis extracted two principal components with eigenvalues higher than one, which accounted for $62.10 \%$ of the total variation (Table 4). First principal component (PC1) contributed to $41.22 \%$ of the total variation and the second principal component (PC2) explained 20.88\% of the total variation. Loadings for PC1 were high for the traits spike length (0.865), spikelet number per spike (0.928), grain number per spike (0.924) and grain weight per spike (0.789). The PC2 loadings were high for awn length ($0.592)$, peduncle length (0.648), 1000 grain weight (-0.401) and grain yield (0.813).

Table 4. Principal Component analysis of 47 mutant lines and their parent varieties

\begin{tabular}{lll}
\hline Traits & PC1 & PC2 \\
\hline Eigenvalues & 3.30 & 1.67 \\
\hline Proportion of variance & 41.22 & 20.88 \\
\hline Cumulative variance & 41.22 & 62.10 \\
\hline & Factor loadings & \\
\hline Spike length & 0.865 & -0.134 \\
\hline Awn length & 0.412 & -0.592 \\
\hline Peduncle length & 0.153 & 0.648 \\
\hline Spikelet number per spike & 0.928 & 0.022 \\
\hline Grain number per spike & 0.924 & 0.133 \\
\hline Grain weight per spike & 0.789 & 0.204 \\
\hline 1000 grain weight & 0.137 & -0.401 \\
\hline Grain yield & 0.014 & 0.813 \\
\hline
\end{tabular}



Figure 2 presents scatter plot of mutant lines and their parent varieties for PC1 and PC2. The mutant lines (17/2-1, 17/1-15, 16/2-7 and 16/1-1) with positive values for PC1 and PC2 had a high number of grains in spike and grain weight per spike combined with high grain yield, but relatively low 1000-grain weight. Parent varieties Zagorets, Kuber and Asparuh had positive values for PC2 and negative for
DYULGEROVA B., et al.

PC1 and variety Imeon had positive values for both PC1 and PC2. All mutants from Zagorets had negative values for $\mathrm{PC} 2$, which showed a grain yield under the average of the studied set of genotypes. Mutant lines (15/1-8, 18/1-4, 18/1-7, 18/2-2, 18/3-7, 15/3-7 and 18/1-6) with negative values for PC1 and PC2 showed lower grain yield and spike productivity.

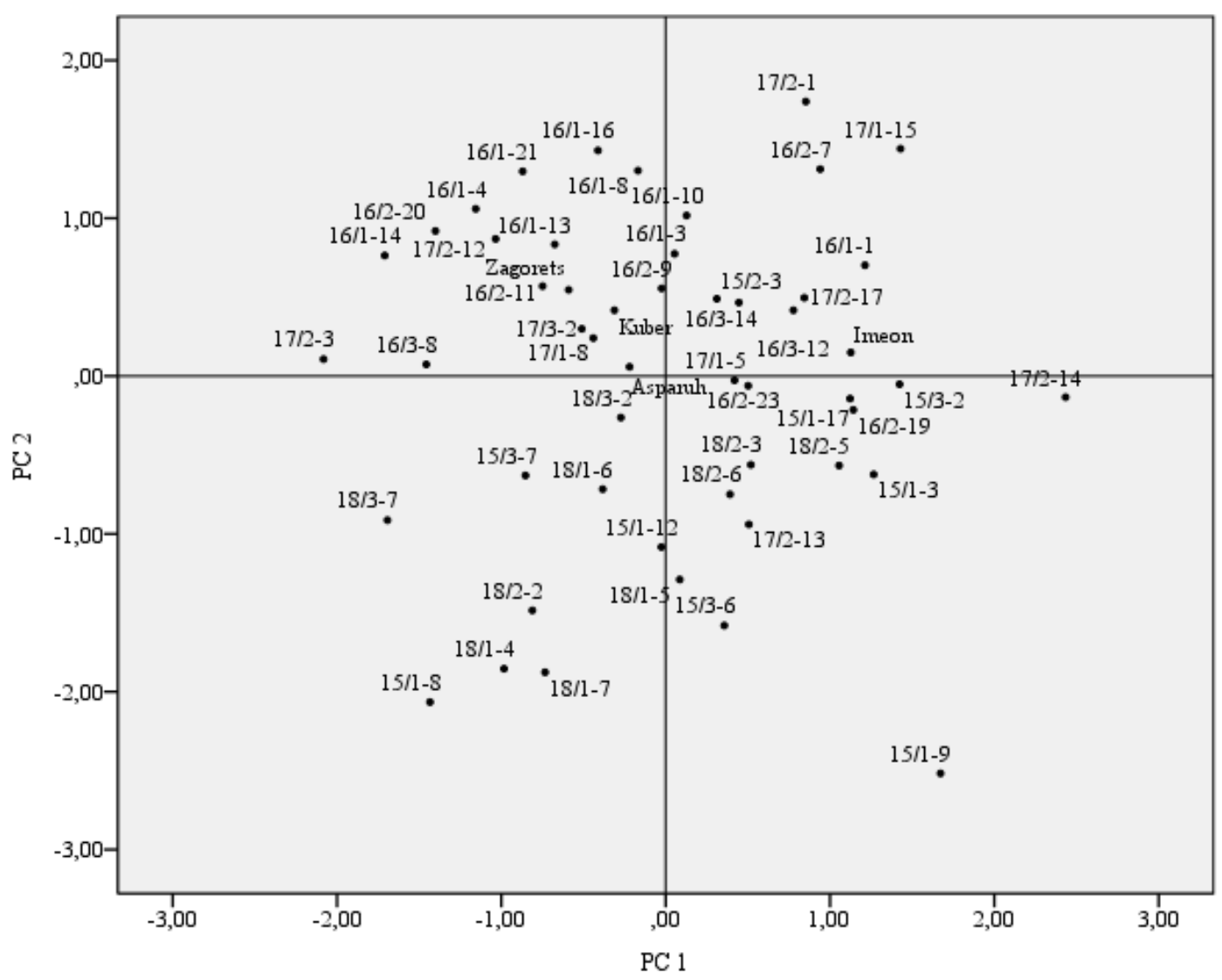

Figure 2. Scatter plot of 47 mutant lines and their parent varieties for first two PCs.

\section{DISCUSSION}

Phenotypic characterization of the mutants is a very important part of mutation breeding program and effective evaluation of the different traits; especially quantitative traits are the key to successful selection. The application of multivariate statistical methods in mutation breeding is of significant importance for classifying the diverse induced mutants according to their genetic relationship. Use of multivariate analysis for identification and classification of mutants has earlier been reported (15-19).

In the present work, multivariate analysis was undertaken primarily to estimate the induced diversity created after mutagenic treatment with chemical mutagen sodium azide compared to the parent varieties on the basis of some yield-related traits. Clustering analysis grouped barley mutants and parents into six different clusters and indicated that mutant lines exhibited notable genetic divergence. A large proportion of mutant lines showed divergence from the parent variety and also among themselves. Among 10 mutants from Zagorets and 18 mutants from Kuber, only 5 (16/1-3, 16/1-8, 16/1-10, 16/1-16, and 16/2) from Zagorets and only one (18/3-2) from Kuber formed a cluster with parent varieties and others were located in clusters other than the parents. Similarly, among 9 mutants from Imeon and 10 mutants from Asparuh, only one (15/2-3) from Imeon and 3 (17/1-8, 17/2-13 and 17/2-14) from Asparuh formed a cluster with parents. The cluster with highest grain yield (Cluster C) included only mutant lines which showed that mutation treatment with sodium azide was efficient for generating mutants with improved quantitative traits. 
In the principal component analysis, the traits associated with PC1 have the largest participation in the divergence between genotypes. In our study traits spike length, spikelet number per a spike, grain number per spike and grain weight per spike contributed most to the variation of the tested mutant lines. Therefore, it can be concluded that mutant treatment was the most effective for altering those traits. In winter feed barley (20) reported that the first principal component was related to yield, grain number and weight per spike, while (21) found that the variation among 106 asseccions of spring barley was mainly due to the variations in plant height, lodging, yield, and 1000 -grain weight.

Cluster analysis and principal component analysis played a complementary role for identification of most promising mutants for using in cross-breeding. It has been shown that more genetically diverse parents are used in the hybridization program; the greater will be the possibilities to acquire a wide range of variations in segregants and to select desired genotypes (22). Therefore the mutants and parents from cluster C and D could be used for crossing with the mutants of clusters $\mathrm{F}$ and $\mathrm{D}$ with the purpose of developing winter barley varieties with improved grain yield. From these methods of grouping, it was evident that many of the mutant lines derived from the same parental variety showed genetic diversity from the parent and also among themselves.

\section{CONCLUSION}

Applied multivariate methods revealed a considerable genetic diversity for important quantitative traits of mutant lines derived from the winter barley varieties Kuber, Zagorets, Asparuh and Imeon. Among the studied traits spike length, spikelet number per spike, grain number per spike and grain weight per spike had the largest contribution to the divergence between mutants. The cluster and principal component analyses employed in the present study divided the mutant lines into different groups, which were deviated significantly from the respective parents. Mutant lines 16/1-3, 16/18, 16/1-21, 16/2-7, 17/2-1 and 17/1-15 can be utilized in hybridization for developing barley genotypes with high grain yield.

\section{REFERENCES}

1. Ahloowalia, B. S., Maluszynski, M. and Nichterlein, K., Global impact of mutation derived varieties. Euphytica, 135:187-204, 2004.

2. FAO/IAEA Mutant Variety Database, https://mvd.iaea.org/ (accessed February 28, 2019), 2019.
DYULGEROVA B., et al.

3. Rahman, M. and Munsur A., Genetic divergence analysis of lime. Journal of Bangladesh Agricultural University, 7(1):3337, 2009.

4. Sabesan, T., Saravanan, K. and Anandan, A., Genetic divergence analysis for certain yield and quality traits in rice (Oryaza sativa L.) grown in irrigated saline low land of Annamalainagar, South India. Journal of Central European Agriculture, 10(4):405410, 2009.

5. Popova, T., Valcheva, D. and Valchev, D., Evaluation of the genotype similarity in tworowed barley genotypes to loose smut. Field Crops Studies, vol.V-1:93-99, 2009.

6. Khodadadi, M., Fotokian, M. H. and Miransari, M., Genetic diversity of wheat (Triticum aestivum L.) genotypes based on cluster and principal component analyses for breeding strategies. Australian Journal of Crop Science, 5(1):17-24, 2011.

7. Desheva, G., Sabeva, M. and Zacharieva, M., Variation of agronomic traits among introduced winter bread wheat cultivars. Trakia Journal of Sciences, 2:171-175, 2016.

8. Rafiq, C., Mahmood, M., Ahmad, M., Ali, I., Shafiq, M., Rasool, I. and Zubair, A., Exploration of Genetic Divergence and Performance of Morpho-Agronomic Traits of Chickpea. Science, 37(4):202-208, 2018.

9. Valchev, D. and Gocheva, M., Biological and Economical Qualities of New Malting Barley Variety Asparuh. Plant Science (Bulgaria) 49(1):13-19, 2012.

10. Valchev, D. and Gocheva, M., Imeon-New Bulgarian Brewing Barley Variety. Plant Science (Bulgaria) 49(1):3-7, 2012.

11. Valchev, D. and Gocheva, M., Winter two rowed malting barley zagorets variety. Plant Science (Bulgaria), 47(3):282-285, 2010.

12. Gocheva, M. and Vulchev, D., Characterisation of winter malting barley cultivar Kuber. Scientific works of Institute of Agriculture - Karnobat, 3(1):71-76, 2014.

13. Ward, J. H., Hierarchical grouping to optimize an objective function. J. Am. Stat. Assoc., 58:236-244, 1963.

14. SPSS Inc., SPSS for Windows. Release 16.0.SPSS Inc. Chicago, IL. USA, 2007.

15. Mahapatra, K., Mishra, C. and Acharya, B., Clustering of rice mutants by different methods of analysis. The Indian Journal of Genetics and Plant Breeding, 55(2):138-147, 1995.

16. Chandra, R., Pradhan, S. K., Singh, S., Bose, L. K. and Singh O. N., Multivariate Analysis in Upland Rice Genotypes. World Journal of Agricultural Sciences, 3 (3):295-300, 2007.

17. Muduli, K. C. and Misra, R. C., Genetic Divergence Analysis among Micromutant 
Lines in Finger Millet (Eleusine coracana G.). J. Crop Sci. Biotech., 11:63-68, 2008.

18. Sarwar, G., Ahmed, H. M. and Hussain, J., Evaluation of castorbean (Ricinus communis L.) mutants for genetic parameters and cluster analysis. Journal of Agricultural Research, 48(3), 289-301, 2010.

19. Tembo, L. and Munyinda, K., Clustering common bean mutants based on heterotic groupings. African Crop Science Journal, 23(1):1-7, 2015.

20. Valcheva, D., Vulchev, D., Popova, T., Dimova, D., Ozturk, I. and Kaya, R.,
DYULGEROVA B., et al. Productive potential of Bulgarian and Turkish varieties and lines of barley in the conditions of Southeast Bulgaria. Trakya University Journal of Natural Sciences, 14(2): 97-102, 2013.

21. Žáková, M., and Benková, M., Characterization of spring barley accessions based on multivariate analysis. Communications in Biometry and Crop Science, 1(2): 124-134, 2006.

22. Arunachalam, V., Genetic distance in plant. Indian Journal of Genetics and Plant Breeding, 41:226-236, 1981. 